Corrections to Met. Trans., 1972, vol. 3

Recrystallization and Grain Growth in $\alpha$ Titanium: I. Characterization of the Structure, by $\mathrm{K}$. Okazaki and $\mathrm{H}$. Conrad, pp. 2411-21.

(The letter $\alpha$ was inadvertently omitted from the title when this paper was published. The correct title is indicated above.)

Page 2414, Figs. 2(a) and 2(b)

The reproduction of Figs. 2(a) and 2(b) was unsatisfactory. The following figures should be substituted:
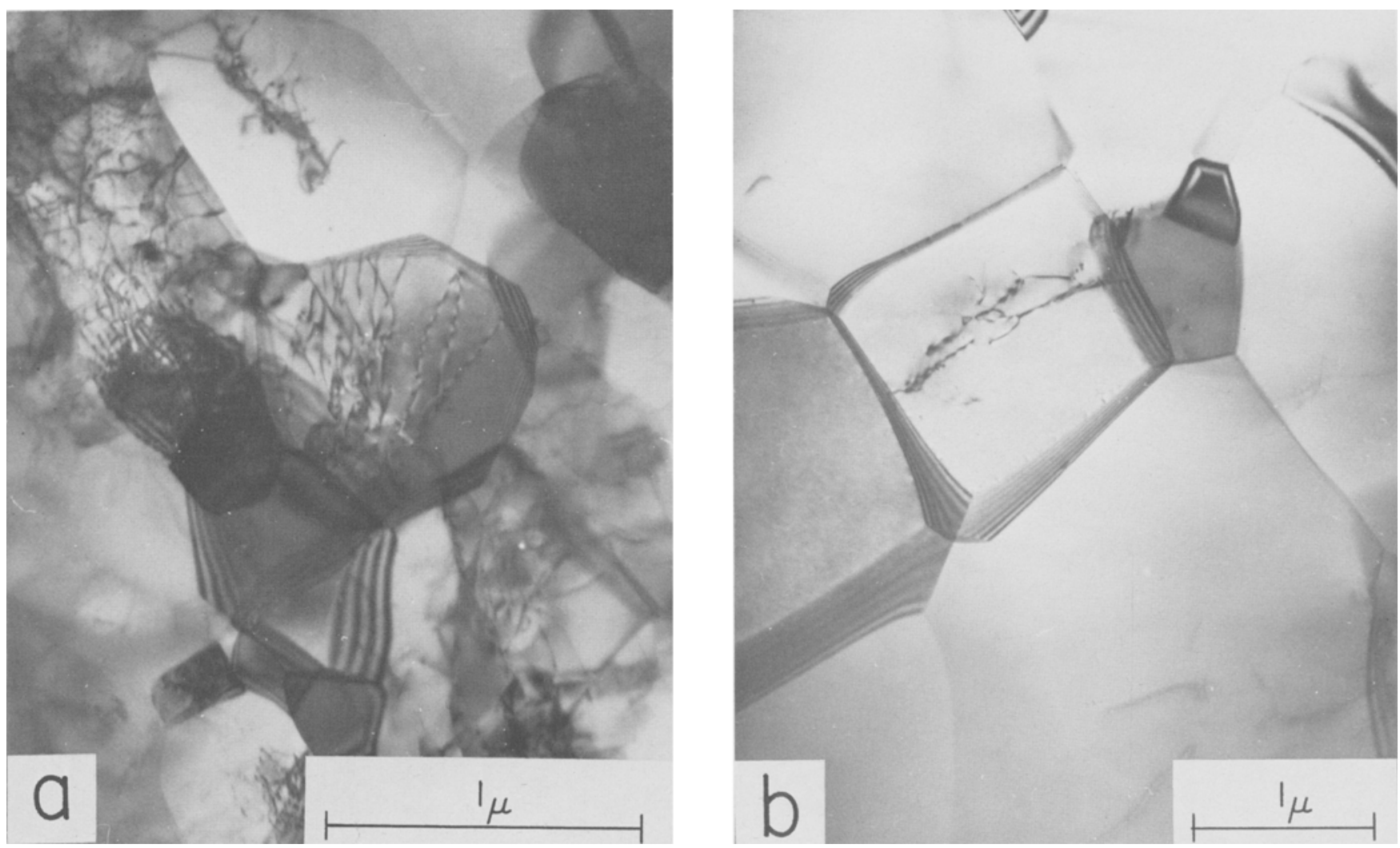

Dopant Observations in Thin Foils of Annealed Tungsten Wire, by D. B. Snow, pp. 2553-54.

\title{
Page 2554
}

The top line of the right-hand column was omitted. The sentence should read as follows:

"The microscope was operated at $100 \mathrm{kv}$, using a $500 \mu \mathrm{m}$ variable condenser aperture, 80 to $120 \mu \mathrm{A}$ beam current at saturation depending on bias setting, and a $2 \mu \mathrm{m}$ beam diam on the foil." 